\title{
ERRO MÉDICO EM CIRURGIA DO APARELHO DIGESTIVO: CONTRIBUIÇÃO PARA O ESTUDO DAS PROVAS TÉCNICAS, PERICIAIS E DOCUMENTAIS E SUAS IMPLICAÇÕES JURÍDICAS
}

\section{Medical malpractice in digestive system surgeries: a contribution to the study of technical, expertise and documentary evidence and its legal implications.}

\author{
João Batista OPITZ Jr, Wiliam Abrão SAAD, Desidério Roberto KISS
}

ABCDDV/520

Opitz Jr JB, Saad WA, Kiss DR. Erro médico em cirurgia do aparelho digestivo: contribuição para o estudo das provas técnicas, periciais e documentais e suas implicações jurídicas ABCD Arq Bras Cir Dig 2007;20(1):23-7.

RESUMO - Racional - A preocupação dos indivíduos em relação aos erros médicos tem aumentado ultimamente entre os brasileiros e muitas vezes processos podem ser evitados com medidas racionais preventivas no relacionamento médico-paciente. Objetivo - Analisar processos judiciais, que tramitam pelos fóruns regionais cíveis do Estado de São Paulo, capital e interior e instituições periciais da capital para definir as principais causas e documentos juntados ao mesmo e conseqüências de cada condição. Métodos - Trinta processos foram analisados onde se fez a extração individualizada de dados. Iniciou-se pela importância prática do tema para efeito de evolução médico-social. Buscou-se estudar a visão da relação médico-paciente, mesmo durante a demanda, a informação ao paciente e seus familiares dos procedimentos e limitadores do ato médico; o documental técnico jurídico juntado ao processo; o preparo técnico-jurídico do médico e, se, a propositura de ação dependia da formação e especialização do profissional. Foram analisados processos judiciais de primeira instância no período de 1996 a 2002 correlacionados às operações do aparelho digestivo. Usou-se como parâmetro de análise exclusivamente os documentos juntados aos autos onde buscou-se a existência clara da quebra da relação médico-paciente, a existência de consentimento informado, a verificação do documental juntado à defesa pelas partes ou solicitação judicial e a qualificação do profissional envolvido nas ações. Resultados - Em 93,34\% dos casos houve quebra da relação médico-paciente. Era visível das partes a animosidade no petitório. Em $10 \%$ dos casos existia consentimento informado, porém, apenas um foi usado e considerado pelo magistrado por descrever e orientar especificadamente sobre o risco que a posteriori originou a demanda. Dois eram genéricos, sendo que não foram considerados, ao ver do julgador, por hiposuficiência do paciente. Em $85 \%$ das vezes não havia história clínica completa. Em $79 \%$ não foi verificada a existência de exame físico. Em $80 \%$ dos casos a letra era ilegível. Em $59 \%$ não foi verificada a existência da evolução clínica. Em $61 \%$ não foram verificadas a identificação ou carimbo do médico. Em $89 \%$ não foi interrogado sobre a existência de alergias prévias. Somente em $20 \%$ dos casos observou-se descrição cirúrgica legível. Em $47 \%$ dos casos as descrições cirúrgicas eram de forma sumária sem as intercorrências alegadas pela defesa. Em $70 \%$ não houve visita pré-anestésica. Em $60 \%$ a prescrição médica de evolução ocorreu com mais que 24 horas no pós-operatório. Em $19 \%$ observou-se administração de medicação pela enfermagem posteriormente à alta médica. Em $64 \%$ dos casos não se observou a descrição das condições de alta. Em 7\% o médico que figura como pólo passivo não possuía residência médica; em 13\% estavam cursando residência ou estágio; em $67 \%$ possuíam título de especialização e em $13 \%$ dos casos mestrado ou doutorado. Conclusão - A melhor forma para profilaxia da ação cível indenizatória por erro médico é a boa relação médico-paciente; a manutenção de prontuário médico preenchido, legível, com carimbo e assinatura; o consentimento informado. A condição técnico-curricular do profissional não é fator atenuante para propositura da ação.

DESCRITORES - Imperícia médica. Erro médico

\section{INTRODUÇÃO}

A preocupação dos indivíduos em relação aos erros médicos não pode ser considerada atual. Desde remotas épocas, o homem já apresenta seu manifesto interesse pelo tema, principalmente na tentativa de regular e controlar o exercício profissional médico, prevenindo a ocorrência de erros através da aplicação de sanções administrativas, civis e penais ${ }^{3}$.

Entretanto, forçoso ressaltar que os erros médicos, no mundo inteiro, estão ficando cada vez mais graves e

Trabalho realizado na Disciplina de Cirurgia do Aparelho Digestivo do Departamento de Gastroenterologia da Faculdade de Medicina da Universidade de São Paulo, São Paulo, Brasil.

Endereço para correspondência: João Batista Opitz Jr. Av. Dr. Arnaldo, 455 - CEP: 01246903 - Cerqueira César - São Paulo - SP, Brasil. constantes, ou, pelo menos, sua constatação e divulgação estão muito mais intensas. São eles cometidos de todas as formas e mínimos são seus controles e prevenções, além da ausência de divulgação estatística.

Para se ter uma idéia, só nos Estados Unidos morrem anualmente cerca de 180.000 pessoas vítimas de erros médicos. O prejuízo financeiro decorrente do problema custa aquele país cerca de quatro bilhões de dólares anuais. Esses dados foram coletados e distribuídos pela Secretaria Nacional de Saúde Americana e pela American Society of Health-System Pharmacists que através de pesquisa telefônica detectaram que três em cada 10 pacientes já sofreram algum tipo de erro médico (esses dados foram obtidos através de solicitação dos autores deste trabalho à Secretaria Nacional e Saúde Americana e à empresa 
de dados Parker \& Waichman Attorney's At Law ${ }^{24}$ ). No Brasil, onde impera a falta de estatísticas, o que estaria acontecendo? Quantos milhares já morreram ou morrem por ano? Quantos já sofreram ou ainda sofrem com algum tipo de erro médico? Só em matéria de infecção hospitalar tem-se triste realidade, pois cerca de 11 milhões de pacientes internados no SUS em 1998, mais de um milhão e meio foram acometidos pela infecção hospitalar.

Como bem salientou o Prof. Dr. William Abrão Saad ${ }^{25}$, no prefácio de recente obra publicada por estes autores, a preocupação orientada à saúde e a higidez física e mental, penetrando nas áreas da intimidade e privacidade humana, é própria do atuar médico, que, em contrapartida, deve estar submetido em seu comportamento profissional, à normatização protetiva dos direitos primários e que exigem tutela específica e ampla.

De tudo resulta que o dano físico ou psíquico ocasionado pelo atuar médico só se legitima pelo procedimento, que deve se apresentar necessário e detalhadamente documentado $^{1,2}$. O domínio desse procedimento, ou seja, da técnica, embasada no conhecimento científico, é fator essencial à exoneração da responsabilidade.

$\mathrm{Na}$ escolha do processo terapêutico, não há dúvida que o médico tem liberdade para empregar, em cada caso, aquele que entenda mais adequado. A liberdade não só significa que o indivíduo tenta a oportunidade e responsabilidade de escolha, mas também, que deve suportar as consequiências de suas ações e receber penalidades ou censuras por elas s, $, 5,6,9$.

Sob o aspecto social, constata-se que o consumidor brasileiro rapidamente se conscientizou dos direitos e prerrogativas que lhe cabiam ${ }^{20,21,22,13,26}$. Em curto espaço de tempo, passou a exigir o cumprimento de obrigações e indenizações por parte do fornecedor de produtos e serviços, que passaram a ser objeto de incontáveis ações de reparação de danos, isto é, de responsabilidade civil e criminal $^{7,8}$.

Nesse universo amplo e heterogêneo de profissionais prestadores de serviços, a figura impar do médico se destaca. Entre outras razões, pelo fato de ele ser o que mais diretamente cuida dos bens maiores do ser humano: sua vida e sua saúde. Hoje, quando frias e insensíveis baterias de exame laboratoriais se sobrepõem à antiga consulta médica - detida, atenta a personalização - não é de admirar que ocorra o desprestígio da classe e a desumanização das relações entre médico e paciente em que este último se torne cada vez mais "impaciente", a ponto de ajuizar violentas ações contra aquele que, em princípio, seria seu maior benfeitor ${ }^{10,11,12,13}$ !

O objetivo deste estudo é estudar a importância do bom relacionamento médico paciente (mesmo durante a demanda); da informação ao paciente e seus familiares; do procedimento e limitadores do ato médico; do documental técnico jurídico científico desde o primeiro atendimento até o processo; do preparo técnico jurídico do médico; de se a propositura de processo depende da formação e especialização do profissional.

\section{MÉTODOS}

Foram analisados 30 processos judiciais que envolviam reparação de danos (indenizações) por erro médico, oriundos de órgãos jurisdicionais diversos (tribunais de justiça estaduais - Fórum cível de São Paulo - Central, Distrital e Interior), e perícias médicas realizadas pelo IMESC - Instituto de Medicina Social e Criminologia do Estado de São Paulo - em processos da mesma espécie no período de 1996 a 2002 exclusivamente na especialidade médica de Cirurgia do Aparelho Digestivo.

Todos os processos tinham decisão judicial de $1^{\mathrm{a}}$ instância ou perícias médicas já realizadas em processos tramitando.

Os itens analisados em cada processo foram: 1) se houve quebra da relação médico-paciente pelo descritivo processual através da análise da inicial e contestação; 2) se havia consentimento informado, verificado nos autos; 3) análise e verificação do documental juntado aos processos: história clínica completa; exame físico; letra legível; evolução clínica; identificação / carimbo; observância de alergias; descrição de cirurgias legíveis; descrição de cirurgias sumárias; visita pré-anestésica; prescrição com mais de 24 horas; alta prescrita antecipadamente; descrição das condições de alta; qualificação do profissional envolvido nas ações se sem residência ou estágio, cursando residência ou estágio, com título de especialista ou não, com mestrado ou doutorado.

Os critérios de inclusão foram processos somente que envolviam doenças e procedimentos relacionados ao aparelho digestivo, processos em andamento na primeira instância em que o médico figurava no pólo passivo e processos em que existiam solicitações de indenização por dano material, moral ou estético.

Para garantir a representatividade e evitar o vício de seleção utilizou-se, na análise estatística, a aleatoriedade da amostra com plano de amostragem probabilística.

\section{RESULTADOS}

Em relação ao bom relacionamento médico-paciente (mesmo durante a demanda), em 93,34\% dos casos houve quebra dessa relação. Era visível das partes a animosidade no petitório, inclusive, em dois casos, isto ocorreu até em audiência quando da tentativa de conciliação marcada pelo Juiz.

Em relação a manter a informação ao paciente e seus familiares do procedimento e limitadores do ato médico, ou seja, existência de consentimento informado nos autos como prova de defesa em $10 \%$ dos casos ele existia, porém apenas um foi usado e considerado pelo magistrado por descrever e orientar especificadamente sobre o risco que a posteriori originou a demanda. Dois eram genéricos, sendo que não foram considerados, ao ver do julgador, por hiposuficiência do paciente. Assim, em $66,6 \%$ dos casos que possuíam consentimento informado, este não foi considerado pelo juiz. 
Em relação à história clínica completa dos prontuários juntados aos autos, em $85 \%$ dos casos ela não existia. Quanto ao exame físico completo dos prontuários juntados, em $79 \%$ dos casos ele também não existia.

Em relação à letra legível nos documentos médicos dos prontuários juntados em $80 \%$ das vezes ela era ilegível.

Em relação à evolução clínica diária nos prontuários juntados aos autos em $59 \%$ dos casos não foi verificada a existência dela.

Identificação e/ou carimbo dos profissionais que atuaram nos prontuários juntados em $61 \%$ dos casos eles não existiam.

Descrição sobre investigação de processos alérgicos nos pacientes constantes dos prontuários juntados aos autos, em $89 \%$ dos casos não foi mencionada a informação sobre a sua existência ou que os pacientes tivessem tido a solicitação de informar.

Em relação à descrição cirúrgica completa legível nos prontuários juntados aos autos, somente em $20 \%$ se observou ser ela legível; ela era sumária em $47 \%$ dos casos sem relato às intercorrências alegadas pela defesa.

Em 70\% dos casos não houve visita pré-anestésica ou descritivo pré-anestésico nos prontuários juntados aos autos.

Prescrição médica de acompanhamento pós-cirúrgico em $60 \%$ dos casos a prescrição médica de evolução ocorreu com mais que 24 horas no pós-operatório.

Alta médica hospitalar antecipada com medicação ministrada pós-alta pela enfermagem descritas nos prontuários, em 19\% dos casos observou-se que ocorreu ministração de medicação pela enfermagem posterior à alta médica.

Descrição das condições de alta no dia da saída do paciente do hospital, em $64 \%$ dos casos ela não foi registrada.

Em relação se a abertura de processo dependia do tempo de formado e especialização do profissional, em $7 \%$ dos casos o médico que figura como pólo passivo não possuía residência médica; em $13 \%$ estavam cursando residência ou estágio; em $67 \%$ possuíam título de especialista e em $13 \%$ possuíam mestrado ou doutorado.

\section{DISCUSSÃO}

\section{Do relacionamento médico-paciente}

Existe grande importância no bom relacionamento médico-paciente (mesmo durante a demanda) ${ }^{14,15}$. O mecanismo de relacionamento pelo qual se estabelece essa relação é sui generis. Na maioria das vezes ela se verifica em decorrência de uma doença. $\mathrm{O}$ motivo que leva o paciente a procurar o médico costuma ser dor, sangramento, febre, enfim, um mal que o aflige. Certamente, só esse fato já cria condições diferentes para o relacionamento. $\mathrm{O}$ doente chega ao médico contrariado por viver uma situação de infortúnio, condição de certa ou muita angústia; entretanto, essa mesma situação de relativa inferioridade leva sem si uma grande dose de esperança ${ }^{16}$.

O primeiro contato talvez seja dos mais importantes momentos e dele vai depender, em grande parte, a boa ou má evolução do referido relacionamento. Se o resultado daquele contato não foi dos melhores, dificilmente o médico conseguirá inspirar confiança a seu paciente. Há de ocorrer nítida empatia entre médico e paciente para que o próprio doente abra seu coração e diga o que precisa ser dito sem constrangimento. Quanto mais fácil for o primeiro contato, mais forte poderá ser o grau de confiança do paciente em seu médico. Este não poderá frustrar nunca as esperanças que o paciente deposita nele. Nesse ponto está a chave do êxito.

O médico não pode criar expectativa maior do que aquela que o doente pode $\operatorname{ter}^{17,18,19}$. Ele deve transmitir esperanças sem criar ilusões. Esse equilíbrio é o que existe de arte no exercer a profissão. Na dose certa do que falar e do que não falar está à habilidade do médico. É de se compreender o quanto é difícil, em cada caso, aquilatar $\mathrm{o}$ adequado procedimento. Nunca se pode esquecer que, no exercício da profissão, o médico não pode ser isolado do homem, com todos os seus méritos, defeitos e problemas.

A mente é muito complexa, motivo pelo qual o comportamento é dificilmente entendido. As relações individuais variam muito e dependem de diversos fatores, entre os quais temperamento, autocontrole, educação e níveis social, econômico e religioso. Certas pessoas, em determinadas circunstâncias, têm manifestações imprevisíveis. Imagine-se-as em um consultório ou hospital. Muitas vezes, o silêncio aparenta tranqüilidade, mas está mascarando grandes emoções. A estabilidade emocional é predicado básico para o médico. Não se pode esquecer o fato de que incidentes corriqueiros, aparentemente banais, podem prejudicar o relacionamento entre pessoas, principalmente quando ofuscadas pela emoção. No consultório ou no hospital, é comum a emoção perturbar tanto o paciente - que escuta o médico mas, às vezes, não o ouve - , e pode nada entender do que lhe foi dito. Tal situação depende muito mais do estado emocional do paciente do que de seu nível intelectual ou de outros fatores. Muito freqüentemente, em sua interpretação, ele distorce tudo o que foi dito, repetindo para o próprio médico exatamente o contrário do que the dissera.

Essa etapa do relacionamento costuma ser vencida na consulta seguinte ou com auxílio de algum acompanhante mais tranqüilo e que realmente esteja empenhado em ajudar o paciente. É difícil fazer que eles e os familiares dêem a cada fato a verdadeira dimensão. O que pode parecer fácil é, na prática, muito difícil. Nessa intrincada complexidade de jogo emocional, com verdades indesejáveis de serem ouvidas, esperanças de milagres inexistentes e recomendações aborrecidas, difíceis de serem seguidas, além de sempre inoportunas, deve o médico envidar todo seu esforço para conquistar a confiança do paciente e dos familiares. Nesse contexto costumam aparecer, para dificultar, filhos que desejam mostrar dedicação e discordam de tudo o que foi feito, menosprezam a dedicação dos vizinhos e relembram todos os casos de malogro ocorridos com seus familiares, para relatá-los pormenorizadamente e, assim, amargurar mais o doente. 


\section{Da interpretação estatística dos dados levantados}

Muitas vezes não é possível na prática se ter plano amostral irrepreensível, pois há muitas situações que dificultam a aplicação dele, como por exemplo na área médica por questões de ética não é possível contar com todos os prontuários nos quais se está interessado. Nesses casos, usa-se um plano amostral não probabilístico, no qual a seleção da amostra depende das características do estudo em questão.

Ao retirar uma amostra não probabilística, deve-se tentar evitar ao máximo a não representatividade dessa amostra na fase de planejamento do estudo, sendo que uma das etapas mais importantes dele é o cálculo do tamanho da amostra. Na amostragem probabilística reúne-se todas as técnicas que usam mecanismos aleatórios na seleção dos elementos da amostra, atribuindo a cada um deles probabilidade conhecida a priori de pertencer à amostra.

Para tirar conclusões válidas sobre a população de estudo a partir dos resultados da amostragem, a maneira estatisticamente correta de escolher os prontuários da população seria por amostragem probabilística. $\mathrm{Na}$ amostragem não probabilística estão os demais procedimentos, tais como amostras intencionais - onde os elementos são selecionados com o auxílio de especialistas - e amostras de voluntários, como ocorre muitas vezes na área médica.
Faz-se este tipo de amostragem, quando é conveniente (ou necessário) tomar uma amostra de prontuários na forma em que eles se apresentam aos pesquisadores. Ambos os planos têm suas vantagens e desvantagens. A principal vantagem da amostra probabilística é de poder medir o erro amostral e conseqüentemente a precisão da amostra obtida, baseando-se nos resultados contidos na própria amostra. Mas a amostragem não probabilística é muito importante, pois possibilita a elaboração de um plano amostral, quando é impossível ou inadequada a utilização da amostragem probabilística.

Para o desenvolvimento deste trabalho foi utilizada a amostragem probabilística "criteriosa", que é a utilização de critérios objetivos na seleção dos prontuários.

\section{CONCLUSÃO}

1. Boa relação médico-paciente até mesmo quando vier a ocorrer demanda judicial, ainda é a melhor proteção para o médico.

2. Manter prontuário médico bem preenchido, legível, sem abreviaturas, com carimbo e assinatura, é importante para a defesa médica (prova documental).

3. O consentimento informado por si só não é suficiente para proteção do médico, mas deve ser elaborado.

4. A condição técnico-curricular do médico não é fator atenuante para a existência da ação judicial.

Opitz Jr JB, Saad WA, Kiss DR. Medical malpractice in digestive system surgeries: a contribution to the study of technical, expertise and documentary evidence and its legal implications. ABCD Arq Bras Cir Dig 2007;20(1):23-7.

ABSTRACT - Background - The fear of being prosecuted by their patients in relation to medical malpractice is growing among brazilian medical doctors. This condition may be avoided with preventive orientations. Aim - To analyze legal proceedings in course in the city and state of São Paulo as well as to define what could be the main cause regarding this concern and its consequences. Methods -Thirty legal proceedings, which were in progress in the regional civil courts in the Capital and countryside of the State of São Paulo - Brazil have been analyzed. Trial court cases were selected from 1996 to 2002 related solely to digestive system surgery. The practical importance of the subject for the medical-social evolution has been addressed in the first place. The points looked for in this research were: physician/patient relationship (even during the claim); the information about medical procedures and limitations to the patient and family; the technical/legal documentation attached to the case; the professional's education and specialization. The analysis was based exclusively on the documents attached to the case record, trying to find the breach of the physician/patient relationship and the existence of informed consent. An examination of the documentation attached to the defense by the parties or court request, was also done. Results - In $93,34 \%$ of the cases rupture in the physician/patient relationship occurred. Informed consent was found in only $10 \%$. In $85 \%$ no or incomplete medical records were found. In 79\%, absence of physical examination, and the same in $59 \%$ in clinical evolution, was noted. In $80 \%$ the writing was illegible. No medical identification was found in $61 \%$. Information about previous allergies were not asked in $89 \%$ of the patients. Surgical descriptions were illegible in $80 \%$ and too brief in $47 \%$, and all of them had no citation of the defense arguments to the malpractice accusation. Regarding medical post-graduation status, $7 \%$ had medical residency, $13 \%$ were in course of residency program, $67 \%$ had specialization certificates and $13 \%$ had a master or phD degree. Conclusion - Among the preventive ways to avoid a civil action for damages due to medical malpractice, the main points are: good relationship between doctors and patients; the formulation of complete patient records, being legible, stamped, and signed and an informed consent. The professional's technical experience and background do not constitute a mitigating circumstance for fullfiling the action.

HEADINGS - Medical malpractice 


\section{REFERÊNCIAS}

1. Aguiar Júnior RR. Responsabilidade civil do médico. Revista dos Tribunais, São Paulo; 1995.

2. Alcântara HR. Responsabilidade médica perante o paciente, o médico, a justiça, o seguro, J.K Editora, Rio de Janeiro;1971.

3. Almeida M, Munhoz DR. A responsabilidade médica: uma visão ética. Revista Bioética, Brasília; 1994.

4. Artigas GV. Minha visão sobre a responsabilidade médica. ARS Curandi. São Paulo; 1991.

5. Bauab JD. A ação do médico e a sua responsabilidade em consulta, tratamento, operação, internação e manutençãodo paciente em hospital. In BITTAR, Carlos Alberto (Coord.). Responsabilidade civil, médica e hospitalar. São Paulo: Saraiva; 1991.

6. Bevilaqua C. Código Civil do Estados Unidos do Brasil. Editora Hist. Rio de Janeiro: Ed. Rio; 1984;4.

7. Bussada W. Erro Médico Interpretado pelos Tribunais, Editora Síntese, São Paulo; 2000.

8. Carmen M. Erro Médico Visto pelos Tribunais, Editora Edipro, São Paulo; 1999.

9. Carvalho JCM. Responsabilidade Civil Médica, Editora Destaque, Rio de Janeiro; 2002.

10. Casilio J. Dano à pessoa e sua indenização,Editora dos Tribunais; 1994.

11. Couto Filho AF. Responsabilidade Civil Médica e Hospitalar, Editora Del Rey, Rio de Janeiro; 2001.
12. Croce DC. Erro Médico e o Direito, Editora Saraiva, São Paulo, 2000.

13. Fernandes B. O Médico e os seus Direitos, Editora Nobel, São Paulo; 1999.

14. França GV. Direito médico. Fundo Editoria BYK, 1978.

15. Giostri HT. Erro Médico. Editora Juruá.Curitiba; 1998.

16. Gordon R. A assustadora história da medicina, 4 ed., Ediouro, 1995.

17. Kfouri Neto M. Responsabilidade Civil do Médico, Editora Revista dos Tribunais, São Paulo; 2001.

18. Machado D. Erro Médico, A Luta Pela Vida, Editora Mauad, Porto Alegre; 2000.

19. Martin LM. O erro médico e a má prática nos códigos brasileiros de ética médica, Revista do Tribunais, 1994.

20. Matielo FZ. Responsabilidade Civil do Médico, Editora Sagra DC Luzzatto, Porto Alegre, 2001.

21. Moraes IN. Erro Médico e a Lei, Editora Lejus, São Paulo; 1998.

22. Pacheco N. O erro médico: a responsabilidade penal, Livrarias do Advogado; 1991.

23. Panasco WL. A responsabilidade civil, penal e ética dos médicos, Editora Forense; 1984.

24. Parker \& Waichman, Attorney's At Law, Dados da Saúde; 2000.

25. Saad WA. Erro Médico - Responsabilidade Civil; 2003.

26. Ramos PLT. Erro Médico. Aspectos jurídicos e médico-legal, Revista dos Tribunais; 1987.

Conflito de interesse: não há

Fonte financiadora: não há

Recebido para publicação em: 07/04/2006

Revisão realizada em: 20/07/2006

Aceito para publicação em: 10/09/2006 